\title{
Энергетическая система человека: эволюция повторного научного открытия
}

\author{
Есть нечто более сильное, чем все войска на свете: это идея, время которой пришло.
}

Виктор Гюго

Статья является логическим продолжением публикации «Энергетическая система человека: что известно официальной науке» (Потяженко М.М., Невойт А.В., 2018). Продолжая проблему необходимости выделения и признания наличия энергетической системы в теле человека, она освещает исторический аспект научных разработок, приведших в XXI в. к открытию ее морфологического субстрата, пониманию анатомической и функциональной организации канально-меридианно-точечной системы перемещения энергии в организме, а также к обоснованию целесообразности внедрения в практическое здравоохранение инновационных методик, базирующихся на оценке биоэлектромагнитной составляющей человеческого организма.

ключевые слова: энергетическая система человека, канально-меридианно-точечная система, первичная сосудистая система.

Здоровье - безусловно, самая большая ценность как для индивидуума, такидля социумав целом. Вэтойсвязи совершенствование методов нозологической диагностики является актуальным направлением в развитии медицины и бесспорно имеет принципиальное значение. Создались научно-технические предпосылки перехода на качественно новый диагностический уровень с применением методик, основанных на оценке биоэлектромагнитных параметров человеческого организма. Для этого наука нашей цивилизации прошла более чем 700-летний путь развития этого направления. Старт начался в XIII в., когда в медицинской практике Европы впервые стали использовать акупунктуру. Метод применяли эмпирически ввиду высокой клинической эффективности, но без принятия его теоретических основ. Суть представлений древневосточных учений о наличии и строении энергетической системы человека игнорировалась западными учеными как лженаучная. Эра освоения нашей цивилизацией электричествадала возможность научной проработки сущности методики и стала собственно периодом рождения электропунктуры. В 1770 г. японский физик, изобретатель, фармацевт Gennai Hiraga создал устройство для генерации статического электричества «Erekiter», предназначенное для использования сочетанно с иглами для акупунктуры. Пионерами электропунктуры в Европе сталиангличанин Perkins (1796), французский врач P. Sarlandier (1825), немецкий профессор, хирургW. von Linhart (1856). В 1864 г. немецкий электротерапевт RobertRemakприменил электрическое воздействие на болевые и болезненные точки. В 1875 г. немецкий врач, естествоиспытатель J.R. von Mayer подтвердил, что гальванизация болевых точек оказывает положительное терапевтическое влияние при невралгии, спазмах, мигрени и др. В 1883 г. профессор, основатель московской клинической школы Г.А. Захарьин и в 1898 г. английский невропатолог Н. Head независимо друг от друга доказали существование связи между кожей и внутренними органами, появление «отраженной» боли. В.А. Подерни в 1938 г. научно доказал, что на всей поверхности кожичеловека существует закономерно ориентированная сеть линий и точек повышенной электрической проводимости, которая топически сохраняется не только при жизни, но и в течение 10-12 ч post mortum. Французский невролог D. de Boulogne в период 1842-1875 гг. создал значительную научную базу относительно электрической активности тканей человеческого организма, разработал неинвазивный метод чрескожной стимуляции, ввел практику увлажнения электродов, а также ряд ключевыхпонятий «электромышечной сократимости», «электрокожной чувствительности», «фарадизации» и др. В 1952 г. советский физиолог А.К. Подшибякин ввел термин «биологически активная точка» (БАТ). По данным его исследований измерений электрического сопротивления кожи стало научно очевидно, что эти точки расположены по траекториям, полностью совпадающим с меридианами, описанными в древнекитайских источниках в VIII-V вв. до н.э. В 1986 г. это было принципиально подтверждено введением технеция в БАТ в Институте Неккера (Франция).
Термины «меридиан» для обозначения каналов и «энергия» как научные эквиваленты древневосточным понятиям ввел в 1955 г. S. Morant. Термин «электропунктура» впервые применил в 1956 г. французский врач R. de la Fuy. Он же в 1957 г. разработал прибор для поверхностного и глубинного воздействия - «электропунктатор».

Множество ученых разных специальностей посветили себя исследованию биоэлектрических свойств человеческого организма и влияния на него электрического тока. Но наиболее фундаментальный вкладв изучение и клиническоеприменениеметода внеслинатом эволюционном этапе врачи R. Voll и Y. Nakatani. R. Voll - немецкий врач-стоматолог, электротерапевт, который в 1953-1989 гг. разработал принципиально новую научную методологию на основе классической китайской акупунктуры, гомеопатии и современныхконцепций физики того времени, открыл новые БАТ и восемь дополнительных к восточной системе меридианов, картировал топику кожновисцеральных связей, разработал и внедрил приемлемуюдля клинического применения методику электрорегистрации с запястья ищиколотки. Его метод обрел мировую известность, разрешен кприменению во многих странах и стал основой для развития в будущем принципиально нового научного направления - биорезонансной медицины. Y. Nakatani - японский врач, с 1950 г. занимавшийся электропунктурой, разработал принципиально иной метод электропунктурнойдиагностики состояния меридианов по репрезентативным точкам. Им установлено, что на меридиане спатологическим органом появляется линия повышенной электропроводности, то есть меридианы проявляют себя как чувствительные «кожные индикаторы» болезней внутреннихорганов. Методполучил название «ридораку»от японского «линия» (цит. по: Ahn A.C. et al., 2008; Петров К.Б., Митичкина Т.В., 2010).

Теоретические изыскания второй половиныХХВ. былипосвящены двум принципиальным вопросам: поиску морфологического субстрата канально-меридианно-точечной системы и разработке современного физиологического обоснования механизмов диагностики и лечебного воздействия электропунктуры. BXX в. J.E.H. Niboyet и A. Mery пришли к выводу, что меридианы объективно существуют и залегают преимущественно в подкожной клетчатке, подтверждением чего является снижение электрического сопротивления кожного покрова в местах их прохождения. Установлено, что этот феномен сохраняется на трупе и даже становится более выраженным после смерти: разницав электрическом сопротивлении между окружающей средой и кожей мертвого человека больше, чем у живого. Установлена также сохранность точек и меридианов не только на целом трупе, но и после его расчленения. В 1963 г. J.E.H. Niboyet определенаплощадьБАТ, равнаяпримерно 1 мм² $^{2}$ Эти факты нашли подтверждение в работах В.Г. Вогралик (1961), Г.М. Покалева (1962), Т. Ischikawa (1962), J.F. Dumitrescu (1967), J. Strongorsarello (1969), G. Cantoni (1970), W. Melhardt (1975) (цит. по: Сергеев Д.В., 1998; Петров К.Б., Митичкина Т.В., 2010). В 1960 г. корейский ученый Kim Bong Ham 
сделал научное сообщение о гистологическом выявлении новой системы «кен-рак», имевшей отличия от нервной и кровеносной. По данным автора, в области БАТ локализованы узелковые образования - «тельца Бон Хана», связанные с трубочками, в которых циркулирует тягучая жидкость со свойствами выраженной электропроводности. Методика его исследования не была на тот момент описана точно, и долгое время не представлялось возможности его повторить (цит. по: Сергеев В.Д., 1998; Коваленко О.Є., Чіжикова М.Є., 2017). Результаты дальнейших исследований подтвердили наличие отличий в тканях области БАТ. Так, в 1964 г. G. Kellner описано, что в БАТ отмечается скопление гетерогенных рецепторов (телец Мейсснера, колбочек Краузе, гломусов) и гладкомышечных волокон в отличие от контрольных участков. В 1959 г. Г.Д. Новинский и соавторь показали, что область БАТ характеризуется наличием более рыхлой соединительной ткани, что обусловливает их физиологические особенности и позволяет с помощью физических приборов определять ихлокализацию. Поданным А.К. Подшибякина (1952; 1960), в области БАТ усилены процессы поглощения кислорода и выделения углекислоты, повышена кожная температура. В 1968 г. G. Grall сделан вывод, что «кожа является только поддержкой и отражением циркуляции более глубокой энергии, токи которой неизменны», поскольку после трансплантации кожного лоскута топография БАТ и меридианов осталась неизменной на рассматриваемыхучастках, апересаженный лоскут потерял свои первоначальные свойства непосредственно после отделения его от региона-донора и со временем приобрел новые электрические характеристики, характерные уже для региона реципиента. Также установлены морфологические особенности кровоснабжения и иннервации БАТ. В 1973 г. J. Bossy в 42\% случаев выявлял в области БАТ подкожный нерв, в 40\% - подкожную вену, в 18\% - подкожную артерию, окруженные периваскулярными нервными сплетениями. P. Rabischong и соавторы в 1975 г. выявили в области БАТ спиралевидные сосудистые сплетения, окруженные безмиелиновыми нервными волокнами холинэргического типа. Данные исследований лаборатории Ф.Г. Портнова 1980 г. показали, что подкожные нервы, артерии и вены имеются в области БАТ примерно в $80 \%$ случаев. Примечательно, что в результатах, полученных Н.И. Вержбицкой и соавторами, прослеживалось определенное принципиальное сходство с полученными Kim Bong Ham: БАТ представляют собой сложный комплекс взаимосвязанных структур «канала» и «локуса». «Канал» состоит из эпителия и волокнистой соединительной ткани, в нем мало клеточных элементов, нервов и сосудов, он связан с островками более рыхлой соединительной ткани, расположенной под подкожными мышцами или среди них. «Локусы» напоминают полиморфные колбы ихарактеризуются более высоким содержанием фибробластов, гистиоцитов, жировых и особенно тучных клеток. Но тогда этот факт не привлек научного внимания. В 1990-х годах полученные морфологические данные позволили Г. Лувсан создать классификацию БАТ по морфологическому принципу: 1) мышечные точки (рецепторы - мышечные веретена); 2) точки в области перехода мышцв сухожилия (рецепторы - сухожильные комплексы Гольджи); 3) точки около сухожилий (рецепторы - пластинчатые тельца); 4) точки около суставной сумки (тип рецептора не выявлен); 5) точки в области волосистой части головы и в других местах (рецепторы - свободные нервные окончания).

Анатомические исследования, проведенные в XX в., позволили заметить в какой-то мере сходство хода меридианов с топографией нервныхстволов и/или сосудов, а такжеходом дерматомов. В разной степени такого рода взглядов придерживались исследователи A.P. Киричинский (1959), R. Fujita (1955), S. de Morant (1955), F. Hubotter, T. Ischikawa (1962), W. Lang (1965). J. Hu, B. Shirota (1966). Квинтэссенцией научной мысли того времени стало определение, данное советским профессором В.Г. Вогралик (1962): «меридиан - это нервные проводники, идущие в покровах тела, оплетающие лимфатические и кровеносные сосуды, мышцы, переходящие затем в нервные сплетения, спинной и головной мозг, а затем - в нервы, идущие к органам» (цит. по: Петров К.Б., Митичкина Т.В., 2010).

Дальнейшее развитие научного поиска сместило акцент в сторону изучения роли соединительной ткани. Причиной этому стали идеи о том, что энергообмен имеет упорядоченныйхарактер во всехтканях организма, а не только в нервной; соединительная ткань имеет повсеместное распространение в организме в виде протяженных на большие расстояния волокнистыхи сетчатыхструктур; химическое строение соединительной ткани обеспечивает ей полупроводниковые свойства и способностьпроводить энергетические потоки. Этагипотеза выдвинута в 1965 г. Н.В. Михайловым. Он также предложил рассматривать энергопроводящую систему соединительной ткани как более древнюю эволюционно и не утраченную человеком в ходе развития (аналогичная имеется у растений), а сформировавшую в сочетании с нервной системой совершенно особый тип рефлекторных связей в организме. В 1958 г. R. Fujita установил совпадение наружной траектории меридианов с реальными «линиями контрактации мышц» (цит. по: Петров К.Б., Митичкина Т.В., 2010). В 1992 г. И.М. Жулев и соавторы, основываясь на данных О. Bergsmann и M. Eder (1982), высказали идею, что «ход почти всех меридианов совпадает с известными функциями мышечных цепочек», а сопряженные меридианы взаимодействуют друг с другом какантагонистические мышечные группы в соответствии с законом реципрокной иннервации Ч. Шерингтона. При этом активация цепочки мышц, соответствующей одному меридиану, через гамма-систему спинного мозга угнетает активность мышечной цепочки другого меридиана.

Параллельно имели место попытки трактовки канальномеридианно-точечной системы с физической и биохимической позиций с целью выяснения принципов ее функционирования. В 1962 г. F. Kracmer высказал предположение, что меридианам соответствует специфическая «биоэлектрическая структура», характеризующаяся тем, что ее поляризационное сопротивление ниже, а поляризационная емкость выше, чем на соседних участках кожи. В 1975 г. A. Lebarbier определил меридианы каклинии электромагнитныхволн, типнематериальныхканалов, неопределяемыханатомически, но легко выявляемых с помощью электронной аппаратуры» (цит. по: Петров К.Б., Митичкина Т.В., 2010). В 1984 г. предложена бифуркационная теория В.А. Ионичевского, показавшего в результате детального топографического анализа связь локализации подавляющего большинства БАТ с местами разветвления кровеносных сосудов или нервов, то есть с теми их участками, где движение крови (а, возможно, и энергии), по мнению исследователя, из ламинарного становится турбулентным. Известно, что данный процесс характеризуется некоторыми энергопотерями, возможно, и определяющими функциональные особенности этих участков.

К концу XX в. установлено, что функционально канальномеридианно-точечная системав значительной мере связана со структурой и функцией различных отделов нервной системы, особенно вегетативной ее части, атакже, что биологическим объектамприсуща естественная неравномерная поляризация - биоэлектретный эффект. Поляризация живых объектов обусловлена способностью тканей генерировать в процессе жизнедеятельности относительно сильные электростатические поля вследствие возникновения некомпенсированного электрического заряда в биологической структуре и имеющие важную физиологическую и информационные функцию в организме. В этой связи в 1988 г. Ю.П. Лиманский сформулировал гипотезу о том, что акупунктурные точки представляют собой специфическую систему, способную адекватно воспринимать ипередавать в мозг сигналы об измененияхэлектромагнитныхполей Земли и метеофакторов, назвав ее «экоцептивной чувствительностью». Эта система представляет собой особый афферентный вход, через который организм постоянно контролирует качественные и количественные параметры факторов внешней среды и в случаях значительных их отклонений может регулировать деятельность жизненно важных функциональных систем организма.

В 1990-х годах продолжено изучение принципов взаимосвязи канально-меридианно-точечной системы с внутренними органами иэндокринно-гуморальной системой организма. Изучением концентраций биологически активных веществ в области БАТ занимались В.С. Гойденко и соавторы (1982), Е.С. Вельховер, Г.В. Кушнир (1983), В.Г. Вогралик (1988). Установлено, чтопри экзогенной илиэндогенной стимуляции БАТ в результате усиления аксонального транспорта из афферентных волокон выделяются такие нейропептиды, как субстанция $\mathrm{P}$ и нейрокинин $\mathrm{A}$, обладающие противовоспалительным эффектом, вызывающие расширение сосудов и повышение их проницаемости. Они также способствуют высвобождению из тучных клеток и лейкоцитов простагландина $\mathrm{E}_{2}$, цитокинов и биогенных аминов, которые, воздействуя на мембрану нервных окончаний, запускают метаболические процессы сенситизации периферических и центральных афферентов, изменяющих возбудимость точек акупунктуры. Регистрация изменений инфракрасного излучения в точках акупунктуры позволила выделить «холодные» и «горячие» 
БАТ. Полярографические измерения напряжения кислорода в тканях выявили снижение уровня микроциркуляции и интенсивности потребления $\mathrm{O}_{2}$ в «холодных» и, соответственно, повышение этих показателей в «горячих» точках (Woolf C.J., 1983; Willis W.D., 1991; Самосюк И.3., Лысенюк В.П., 1994; Woolf C.J., Doubell T.P., 1994; Woolf C.J., Salter M.W., 2000). Установлено, что при острых воспалительных процессах в аурикулярных точках, корреспондирующих пораженный орган, повышается порог болевой и температурной чувствительности, электропроводности, сопротивления, электрической емкости и потенциала относительно интактных участков кожи, а при хроническом, вялом течении заболевания и при новообразованияхвыявляется понижение этих параметров. При этом визуально отмечаются локальные неспецифические морфологические признаки, такие как гиперемия, пигментация или скарификация кожи (Портнов Ф.Г., 1980; Вельховер Е.С., Кушнир Г.В., 1983; Качан А.Т., 1990; Лувсан Г., 1990). К концу ХХ В. по определению Института земного магнетизма, ионосферы и распространения радиоволн Российской академии наук БАТ рассматривались как «области эпидермиса диаметром 2-3 мм (слегка меняющиеся в зависимости от внутренней и внешней температуры, а также общего состояния вегетативной нервной системы), характеризующиесяповышенной концентрацией капилляров и нервных окончаний, мелких лимфатических протоков и целым рядом необычных физических и физиологических свойств. ДляБАТ характерно повышенное выделение углекислого газа, повышенная температура (на $0,2^{\circ} \mathrm{C}$ ) и пониженное сопротивление (около 100 кОм в норме). Через соответствующие участки спинного мозга каждая точка связана с функцией определенного органа. При заболевании органа связанная с ним поверхностная точка становится тактильно болезненной, а все вышеперечисленные параметры БАТ отклоняются от нормальных значений. Многотысячелетний опыт китайской народной медицины показал, что система БАТ позволяет получать информацию о функционировании как отдельного органа, так и всего организма в целом, и активно воздействовать на соответствующую патологию. Таким образом, система акупунктурных точек проявляет себя как прекрасно развитый природой диагностический и терапевтический аппарат» (Рагульская М.В., Любимов В.В., 2000).

B XXI в. появилась возможность применения биомедицинских имиджинговых технологий, благодаря которым в организме человека открыта ранее не известная анатомическая структура, получившая научноеназваниепервичной сосудистой системы (англ. Primo Vascular System) и являющаяся, по мнению ученых, морфологическим субстратом энергетической системы. Открытие стало возможным благодаря результатам стартовавшего в 2002 г. в Западной Корее проекта поиска системы «кен-ран» под руководством профессора K.-S. Soh Аналогичные исследования одновременно проведеныпрофессором Kyung Kang (США) и D.K. Harrison (Великобритания). В 2010 г. состоялся Первый международный симпозиум, посвященный результатам исследования первичной сосудистой системы, и основано Международное общество по ее изучению. В целом, на современном методологическом уровне подтверждено морфологическое различие между зонами точек акупунктуры/БАТ и свободной ткани, детально описана сама первичная сосудистая система. Полученные данные созвучны описанию результатов исследований Kim Bong Ham и Н.И. Вержбицкой и соавторами. По данным K.-S. Soh (2009), K.-S. Soh и соавторов (2012), M. Stefanov и соавторов (2013), первичная сосудистая система представлена первичными микрососудами и микроузлами, имеет шестиуровневое строение: поверхностный слой находится в коже, экстраваскулярный - вдоль крупных кровеносных сосудов, интраваскулярный - в кровеносных сосудах, собственно в середине крупных вен, артерий и лимфатических сосудов, но не прикрепляется к сосудистой стенке, органно-поверхностный на поверхности внутренних органов, внутриорганный - в середине внутренних органов, нейтральный слой находится в середине спинного, головного мозга и около периферических нервов. Первичные микрососуды в 10-20 раз тоньше, чем лимфатические, и представляют собой прерывающиеся линии с дополнительными каналами внутри, стержнеподобными ядрами и наружной мембранойсвысоким содержанием гиалуроновой кислоты. Установлено, что внутри первичных сосудов циркулирует жидкость, содержащая предшественники стволовых клеток, гормонов, аминокислот, липидов, гиалуроновой кислоты, и обладающая выраженным стимулирующим действием на ткани. По биохимическим составляющим первичная сосудистая система подобна системе стволовых клеток. Она очень сложна для визуализации, поскольку имеет очень малые размеры и прозрачна (Lee S.J. et al., 2008; Stefanov M. et al., 2013; Stefanov M., Kim J., 2015). Клетки первичных сосудов являются электрически активными, имеют $\mathrm{Ca}^{2+}$-каналы, М-рецепторы в первичных узлах и способны распространять электрический импульс подобно мышечным (Ahn A.C. et al., 2008; Sang Hyun Park et al., 2013). Согласно выводам K.-S. Soh, первичная сосудистая система является сеткой оптических каналов с гранулами ДНК внутри, которая паутиноподобно представлена в организме и можетбыть источником и транспортной системой биофотонов. Согласно современным научным представлениям, фотон - фундаментальная частица магнитного поля, выделяемая возбужденным атомом или молекулой (Tinsley J.N. et al., 2016). По первичной сосудистой системе биофотоны/«жизненная энергия»/«энергия ци» может перемещаться к органам, активируя их ткани. Это соответствует восточным представлениям о действии акупунктуры (Soh K.-S., 2004; Avijgan M., 2013).

XXI в. стал успешным также для обобщения и упорядочения знаний организации канально-меридианно-точечной системы на макроуровне. Как оказалось, в ходе меридианов нет ничего от мистики, нет ничего противоречащего современным медицинским знаниям и законам здравого смысла. В этом легко убедиться, ознакомившись с монографией российских ученых К.Б. Петрова, Т.В. Митичкиной «Миовисцерофасциальные связи в традиционном и современном представлении» (2010). Ими обобщены принципиальные наработки более ранних научных открытий и изложена концепция энергетической взаимосвязи в организме, построенная на принципе функционально-анатомически-топического взаимодействия цепочки из мышц, соединительной ткани и органов. В монографии на современном научно-методическом уровне изложена четкая топика, согласно мышечному и фасциальному расположению каждого из существующих меридианов. Соответственно авторами выделено 12 миотатических синкинезий и наиболее типичные ихобъединения. Мышечные цепи посредством фиброзных мембран соединены с соответствующими ходу внутренними органами, образуя единую сеть миовисцеральных связей, охватывающую все тело и принимающую участие в регуляции его функций. При этом соединительнотканные мембраны (фасции, капсулы, апоневрозы и т.п.) рассматриваются как объединяющая система - «фиброзныйскелет», обеспечивающий связь и энергоинформационный взаимообмен в организме. Правоту подобной концепцииподтверждает наличие усоединительнойткани пьезоэлектрических свойств, ее участие в иммунитете, регуляции клеточного обмена веществ.

Таким образом, окончательное научное подтверждение в XXI в. объективного наличия канально-меридианно-точечной системы в организме человека в сочетании с такими фундаментальными открытиями физики, как: 1) функция живых клеток генерировать под влиянием метаболических процессов ритмически изменяющийся, индивидуальный для каждого типа ткани электростатический заряд; 2) способность образовывать собственные эндогенные переменные электромагнитные поля фрелиховско-давыдовского типа, обладающие, подобно лазерному излучению, высокой степенью когерентности (цит. по: Полякова И.П., 2011); 3) способность биоэлектромагнитных полей автоматически модулироваться структурой биосистемы, нести очевидную кодово-частотную информацию (Давыдов А.С., 1984; Scholkmann F. et al., 2013) и 4) способность излучать фотоны сверхнизкой интенсивностибезвнешнейстимуляции, такназываемая сверхслабая эмиссия фотонов (англ. ultra-weak photon emission) (Cifra M., Pospíšil P., 2014; Salari V. et al., 2015; Tinsley J.N. et al., 2016) открывают принципиально новый научный уровень знаний относительно функционирования человеческого организма. Это, наряду с накопленным 70-летним опытом визуализации магнитного поля человека в высокочастотном электрическом разряде, 69-летним опытом электропунктуры современного уровня, 56-летним опытом магнитокардиографии, 51-летним опытом магнитоэнцефалографии, создает научный базис для дальнейшего широкого внедрения биоэнергетического направления в практическую медицину и демонстрирует научно-практическую целесообразность его дальнейшего изучения и использования в рутинной диагностике (Потяженко М.М., Невойт А.В., 2018; 2019). Переднами, учеными-медиками современности, теперь стоит задача ресинтеза имеющегося научного пласта наработанных знаний с последующей их дальнейшей интеграцией в фундаментальную и практическую медицину. Выражаем мнение, 
что это один из основных путей современного и реального научного поиска, который может привестичеловечество к решениюпроблемы неинфекционных заболеваний.

\section{Список использованной литературы}

Вельховер Е.С., Кушнир Г.В. (1983) Экстерорецепторы кожи. Штиинца, Кишинев, 125 с.

Вогралик В.Г. (1961) Основы китайского лечебного метода чжень-цзю. Горьковское книжное издательство, Горький, 320 с.

Вогралик В.Г., Вогралик М.В. (1998) Пунктурная рефлексотерапия. Чженьцзю. Волго-Вятское книжное издательство, Горький, 307 с

Гойденко В.С., Котенева В.М., Ситель А.Б. (1982) Нейрофизиологические основы рефлексотерапии. РМАПО, Москва, 22 с. $288 \mathrm{c}$.

Давыдов А.С. (1984) Солитоны в молекулярных системах. Наукова думка, Киев,

Жулев Н.М., Лобзин В.С., Бадзгарадзе Ю.Д. (1992) Мануальная и рефлекторная терапия в вертеброневрологии. Санкт-Петербург, 586 с.

Ионичевский В.А. (1984) Критический анализ классических и современных представлений о точках «пяти первоэлементов» в системе точек акупунктуры. Препринт, Хабаровск, 49 c.

Качан А.Т. (1990) Анатомо-топографическое расположение корпоральных точек акупунктуры и показания к их применению. Изд-во Воронеж. ун-та, Воронеж, $127 \mathrm{c}$.

Коваленко О.є., Чіжикова М.є. (2017) Сучасні погляди на субстрат та механізми дії акупунктури. Міжнар. неврол. журн., 6: 120-126.

Лиманский Ю.П., Мачерет Е.Л., Ващенко Е.А. (1988) Неврологические синдромы остеохондроза. Здоровье, Киев, 155 с.

Лувсан Г. (1990) Традиционные и современные аспекты восточной рефлексотерапии: 2-е изд., перераб. Наука, Москва, 576 с.

Лувсан Г. (1991) Очерки методов восточной рефлексотерапии: 3-е изд., перераб. и доп. Наука (Сиб. отд-ние), Новосибирск, 432 с.

Михайлов Н.В. (1985) Механизм лечебно-стимулирующего действия луча лазера на организм животных и повышение их продуктивности. Изд-во Казанского ун-та, Казань, 199 с.

Новинский Г.Д., Воробьева И.А., Воробьев Л.Н. (1960) О новыхприборах и методах нахождения китайских точек. Вопросы нейроэндокринной патологии и рефлекторной терапии: Сб. трудов. Волго-Вятское книжное изд-во, Горький, 72-73.

Петров К.Б., Митичкина Т.В. (2010) Миовисцерофасциальные связи в традиционном и современном представлении. Полиграфист, Новокузнецк, $221 \mathrm{c.}$

Подшибякин А.К. (1955) Об изменении электрических потенциалов во внутренних органах и в связанных с ними активных точках. Физиол. журн. СССР, 3 351-362.

Покалев Г.М. (1962) Влияние иглоукалывания на проницаемость сосудов и тканевой обмен. Сборник трудов Горьковского мед. института, 9: 124-136.

Полякова И.П. (2011) Магнитокардиография: историческая справка, современное состояние и перспективы клинического применения. Креатив. кардиол., 2 103-133. $352 \mathrm{c}$.

Портнов Ф.Г. (1980) Электропунктурная рефлексотерапия. Зинатне, Рига

Потяженко М.М., Невойт А.В. (2018) Энергетическая система человека: что известно официальной науке. Укр. мед. часопис, 6(2) (128): 22-24 (https://www.umj. com.ua/article/132362).

Потяженко М.М., Невойт А.В. (2019) Неинфекционные заболевания: поиск альтернативных решений проблемы с биофизических позиций. Практ. лікар 1: 58-62.

Рагульская М.В., Любимов В.В. (2000) Приборное изучение воздействий естественных магнитных полей на БАТ человека: методы, средства, результаты. Журн. радиоэлектрон., 11: 115-120.

Самосюк И.3., Лысенюк В.П. (1993) Методы восточной диагностики по языку и животу. Здоров'я, Киев, 18 с.

Самосюк И.З., Лысенюк В.П. (1994) Акупунктура: Энциклопедия. АСТ-Пресс, Москва, 543 с.

Сергеев Д.В. (1998) Эволюция представлений о морфологическом субстрате биологически активных точек и энергетических меридианов в системе китайской классической чжень-цзю-терапии. Матем. морфол., 3(1): 166-179.

Ahn A.C., Colbert A.P., Anderson B.J. et al. (2008) Electrical properties of acupuncture points and meridians: a systematic review. Bioelectromagnetics, 29(4) 245-256.

Avijgan M. (2013) Can the Primo Vascular System (Bong Han Duct System) be a Basic Concept for Qi Production? Int. J. Integr. Med., 1: 1-10.

Bergsmann O., Eder M. (1982) Funktionelle Pathologie und Klinik der Brastwilbersдule. Gustav Fischer Verlag, Stuttgart, N.Y., 167 p.

Cifra M., Pospišil P. (2014) Ultra-weak photon emission from biological samples: definition, mechanisms, properties, detection and applications. J. Photochem. Photobiol., 139: 2-10.

Kellner G. (1966) Bau und Funktion der Haut. Dtsch. Z. Acup., 15: 1-31.

Lee S.J., Lee B.Ch., Nam Ch.H. et al. (2008) Proteomic analysis for tissue and liquid from Bonghan ducts on rabbit intestinal surfaces. J. Acupunct. Merid. Stud., 1(2): 97-109.
Niboyet J.E.H., Mery A. (1958) Compte rendu de recherches experimentales sur les meridiens. In: Actes des III Journ. Intern. d'Acupuncture: 47-51.

Niboyet J.E.H. (1963) La moindre resistanse al'elektrisite de surfases punctiformes et de trajets cutanes concordants aves les point et meridiens bases de l'acupuncture. Jean Gap., 112 S.

Salari V., Valian H., Bassereh H. et al. (2015) Ultraweak Photon Emission in the Brain. J. Integr. Neurosci., 14: 419-429.

Sang Hyun Park, Eung Hwi Kim, Ho Jong Chang et al. (2013) History of Bioelectrical Study and the Electrophysiology of the Primo Vascular System. Evidence-based Complementary and Alternative Medicine, 14.

Scholkmann F., Fels D., Cifra M. (2013) Non-Chemical and Non-Contact Cellto-Cell Communication: A Short Review. Am. J. Trans. Res., 5: 586-593.

Soh K.-S. (2004) Bonghan Duct and Acupuncture Meridian as Optical Channel of Biophoton. J. Korean Phys. Soc., 45(5): 1196-1198.

Soh K.-S. (2009) Bonghan Circulatory System as an Extension of Acupuncture Meridians. J. Acupunct. Merid. Stud., 2(2): 93-106.

Soh K. -S., Kang K.A., Harrison D.K. (2012) The Primo Vascular System. Its role in cancer and regeneration: a textbook. Springer, $336 \mathrm{p}$.

Stefanov M., Kim J. (2015) Visualizing the Peripheral Primo Vascular Systemin Mice Skin by Using the Polymer Mercox. J. Pharmacopunct., 18(3): 75-79.

Stefanov M., Potroz M. , Kim J. et al. (2013) The Primo Vascular system as a New Anatomic System. J. Acupunct. Merid. Stud., 6(6): 331-338.

Tinsley J.N., Molodtsov M.I., Prevedel R. et al. (2016) Direct Detection of a Single Photon by Humans. Nat. Commun., 7: 12-17.

Willis W.D., Coggeshall R.E. (1991) Sensory mechanisms of the spinal cord. Plenum Press, New York, $286 \mathrm{p}$.

Woolf C.J. (1983) Evidence for a central component of post-injury pain hypersensivity. Nature, 306(1): 686-688.

Woolf C.J., Doubell T.P. (1994) The pathophysiology of chronic pain - increased sensivity to low the shold A bet-fibre inputs. Curr. Opin. Neurobiol., 4: 25-34.

Woolf C.J., Salter M.W. (2000) Neuronal plasticity - increasing the gain in pain. Science, 288: 1765-1768.

\section{Енергетична система людини: еволюція повторного наукового відкриття М.М. Потяженко, Г.В. Невойт}

Резюме. Стаття $є$ логічним продовженням публікації «Енергетична система людини: що відомо офіційній науці» (Потяженко М.M., Невойт Г.В., 2018). Продовжуючи проблему необхідності виділення і визнання наявності енергетичної системи в тілі людини, публікація висвітлює історичний аспект наукових розробок, що привели у XXI ст. до відкриття морфологічного субстрату, розуміння анатомічної та функціональної організації канально-меридіано-точкової системи переміщення енергії в організмі, а також до обгрунтування доцільності впровадження упрактичну охоронуздоров'я інноваційнихметодик, якібазуються на оцінці біоелектромагнітної складової людського організму.

Ключові слова: енергетична система людини, канально-меридіаноточкова система, первинна судинна система.

\section{Human energy system: evolution of repeated scientific opening \\ M.M. Potyazhenko, A.V. Nevoit}

Summary. The article is a logical continuation of the publication «Human energy system: what is known to the official science" (Potyazhenko M.M., Nevoyt A.V., 2018). It continues to raise the problem of the need to highlight and recognize the presence of the energy system in the human body. The authors will cover the historical aspect of scientific developments that led to the discovery of a morphological substrate, understanding of the anatomical and functional organization of channel-meridian-point system in the twenty-first century. The authors substantiate in the article the expediency of introducing innovative methods of evaluation of the bioelectromagnetic component of the human body into practical health care.

Key words: human energy system, channel-meridian-point system, primary vascular system.

\section{Адрес для переписки:}

Потяженко Максим Макарович

36011, Полтава, ул. Шевченко, 23

Украинская медицинская стоматологическая академия

кафедра внутренних болезней и медицины неотложных состояний

с кожными и венерическими болезнями

E-mail: umsainua@ukr.net

Получено 28.02.2019 